\title{
Resistance to thyrotropin-releasing hormone syndrome
}

INSERM

\section{Source}

INSERM. (1999). Orphanet: an online rare disease and orphan drug data base. Resistance to thyrotropin-releasing hormone syndrome. ORPHA:99832

Resistance to thyrotropin-releasing hormone (TRH) syndrome is a type of central congenital hypothyroidism (see this term) characterized by low levels of thyroid hormones due to insufficient release of thyroid-stimulating hormone (TSH) caused by pituitary resistance to TRH. It may or may not be observed from birth. 